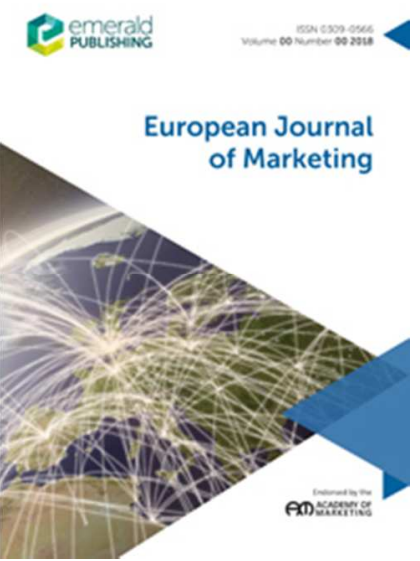

\title{
Intersectional research stories of responsibilising the family for food, feeding and health in the twenty-first century
}

\begin{tabular}{|r|l|}
\hline Journal: & European Journal of Marketing \\
\hline Manuscript ID & EJM-06-2018-0394 \\
\hline Manuscript Type: & Original Article \\
\hline Keywords: & $\begin{array}{l}\text { Family, food, responsibilisation, gendered work, feeding the family, Family, } \\
\text { Food, Responsibilisation, Gendered work, Feeding the family }\end{array}$ \\
\hline
\end{tabular}


Families and Food: Marketing, Consuming and Managing

Introductory viewpoint for EJM Special Issue

\title{
Intersectional research stories of responsibilising the family for food, feeding and health in the twenty-first century
}

Teresa Davis, Margaret K. Hogg, David Marshall, Alan Petersen and Tanja Schneider ${ }^{1}$.

\begin{abstract}
- Purpose: Literature from across the social sciences and research evidence are used to highlight interdisciplinary and intersectional research approaches to food and family. Responsibilisation emerges as an important thematic thread as family has (compared with the state and corporations) been increasingly made responsible for its members' health and diet.
\end{abstract}

- Approach: Three questions are addressed. First, the extent to which food is fundamentally social, and integral to family identity, as reflected in the sociology of food; Second, how debates about families and food are embedded in global, political and market systems; and thirdly, how food work and caring became constructed as gendered.

- Findings: Interest in food can be traced back to early explorations of class, political economy, the development of commodity culture, and gender relations. Research across the social sciences and humanities draw on concepts that are implicitly sociological. Food production, mortality and dietary patterns are inextricably linked to the economic/social organization of capitalist societies, including its gender-based divisions of domestic labour. DeVault's (1991) groundbreaking work reveals the physical and emotional work of providing / feeding families and highlights both its class and gendered dimensions. Family

\footnotetext{
1 University of Sydney; Lancaster University; Edinburgh University; Monash University; and University of St. Gallen.
} 
mealtime practices have come to play a key role in the emotional reinforcement of the idea of the nuclear family.

- Originality/value: Highlights the imperative to take pluri-disciplinary and intersectional approaches to researching food and family. Additionally, this article emphasizes that feeding the family is an inherently political, moral, ethical, social and emotional process, frequently associated with gendered constructions.

Keywords: Family, food, responsibilisation, gendered work, feeding the family.

\section{Introduction}

Many academic and popular stories have already been written about families, and specifically how their entwined interactions with food contribute to making families and family life. So the question might be, why revisit these well-established topics and this well-trodden ground? The invited research viewpoints and the articles in this special issue really answer this question - illustrating how our changing understanding of families and food draws on a range of theories from across the social sciences. Responsibilisation thus emerges both explicitly and implicitly from many of the stories told here. The family has moved centre-stage (compared with the state and corporations) in taking responsibility for family health and diet.

In this introductory research viewpoint, and reflecting on our own interdisciplinary work on families and food as part of a Leverhulme funded Family Food Project ${ }^{\mathrm{i}}$, we explore contributions largely from sociology and political economy to the study of family food consumption. Essentially, we want to address three areas that are relevant to intersectional research and responsibilisation; first the extent to which food is fundamentally social, and integral to family identity, as reflected in the sociology of food; second the extent to which it is embedded in global political and market 
systems; and third, the gendered nature of food work and caring. We begin by looking at how the sociology of food and family is embedded in the social and industrial global food systems. We then highlight the essentially political nature of both the idea of family and the way food is consumed, arguing that the responsibility for health has shifted from the state to the individual and the family. Finally, we revisit the gendered nature of food work and reflect on where the burden of food work and responsibility lies in the contemporary family unit by looking at issues around mothers' and fathers' responsibilities for family food and feeding.

\section{A sociology of family, food and health}

The sociological literature on food is highly diverse and rapidly expanding. It includes investigations of the contexts and practices of food consumption, the political economy of food production, the work of feeding families, the meanings attached to certain food items or to practices of eating, the inequalities arising from different access to particular diets, the social conditions underpinning food anxieties and the 'moral panics' surrounding changing eating practices (Murcott, Belasco and Warren, 2013; Murcott, 2012; Jackson, 2018). However, sociological interest in food is not new and can be traced back to early explorations of class, political economy, the development of commodity culture, and gender relations. Despite claims by Mennell, Murcott and Van Otterloo, in their 1992 introduction to The Sociology of Food, that 'food as such is only of passing interest to Marx’ (see also Bellamy, Monthly Review, 2016), Marx provides a seminal contribution in his critique of the industrial food system in Britain in the mid-nineteenth century. Perhaps better known and more influential is Bourdieu's (1984, originally published in 1979) analysis of the class-related cultural and symbolic significance of food practices, showing how eating and drinking habits were integral to the lifestyle of classes and to masculine and feminine identities. DeVault's (1991) feminist exploration, Feeding the Family, is also groundbreaking in revealing the hard physical and emotional work involved in providing for and feeding families and in highlighting class and 
gendered dimensions. While these contributions are generally considered to be sociological, one should not overlook that sociology comprises multiple perspectives and has permeable boundaries. Hence, anthropologists, cultural theorists, media and communication analysts, historians, public health and health promotion scholars, gender theorists, geographers and marketing scholars have all drawn variously on ideas and concepts that may be considered broadly sociological, even if not explicitly labeled as such.

What specifically does sociology have to offer the study of food, families, and marketing? The discipline offers a distinctive set of perspectives, questions and methodological approaches to this field, challenging the reductionism of the dominant biomedical and psychological paradigms that focus on biophysical and cognitive or behavioural factors. This reductionism is evident, for example, in the discourse of the 'obesity epidemic' that tends to be posited as an individual behavioural 'failure' or a product of 'obesogenic environment' in the absence of any analysis of the dynamics of food markets, food marketing practices, and the changing socio-historical conditions shaping conceptions of the 'normal, healthy' body and a 'nutritious diet'. The 'sociological imagination' (Mills, 2000; orig.1959) draws attention to the inextricable links between individual identities and experiences (or 'private troubles' and pleasures), on the one hand, and wider social structures and historical contexts, on the other. The latter includes exploration of the workings of politics and power, political economy, and the deceptive and manipulative practices of marketing (e.g. Akerloff and Shiller, 2015). However, empirical research and writing on food has tended to bifurcate between 'micro' level analyses of individual perspectives and experiences (e.g. of food and diet) (typically revealed through ethnographies and narrative accounts) and of family dynamics, and 'macro' analyses of the conditions shaping the production, distribution, and consumption of food and nutritional practices.

Doyal's (1979) influential The Political Economy of Health, while not generally acknowledged as a contribution to the sociology of food per se, is important in showing how food production and mortality and morbidity related dietary patterns are inextricably linked to the 
economic and social organization of capitalist societies, including its gender-based divisions of domestic labour. The work offers a thoroughgoing analysis of the historical and global politicoeconomic context that is lacking in much recent sociological and other social science studies of food. As Doyal argues, food is essential to survival and yet is also 'produced for profit, and the transformation of food into a commodity has had profound effects on what is produced, how it is produced and how it is distributed.' (1979 p. 83). The mechanization and concentration of food production has profoundly shaped what we eat, with highly processed food being far removed from their agricultural sources, posing significant health risks. As Doyal argues, in capitalist societies, advertising serves a crucial role in creating 'needs' for particular foods that often prove to be unhealthy (1979 pp. 87-95).

Sociology offers valuable insights into the implications of the changing techniques of marketing in a context in which media is increasingly multifarious, interactive and 'user-generated'. That the crucial role played by advertising and the application of its techniques in 'social marketing' is shaping views on food and diets is demonstrated in the work of writers such as Levenstein (2012), who analyses the constantly changing advice on food and diet. Similarly, Foxcroft's (2011) history of dieting over 2,000 years; as well as in Scrinis' (2013) treatise on the science and politics of dietary advice ('nutritionism') build on this. While these particular writers do not self-identify as sociologists, in showing how advertising serves to create and sustain markets for particular foods and diets and, in some cases, contributes to the social anxieties surrounding eating and nutritional advice ('food scares', 'food fears', allergies) their writings reveal the workings of a strong sociological imagination. The contributions of the geographer Peter Jackson, too, are sociologically notable, in revealing the contexts and conditions shaping community-wide anxieties about food and its safety (e.g. Jackson, 2015, 2018; Jackson and Everts, 2010).

In analysing the wider contexts within which food is produced, marketed, and consumed, sociologists serve to debunk taken-for-granted concepts of 'food' and 'nutrition', by showing that these, and related practices, vary through time and across societies and cultures, and between 
classes, genders, and other social groups. Moreover, notions of the 'healthy diet' and dietary advice promulgated avowedly for the 'public good' have been shown to contribute to the 'moralization of risk' (Hier, 2008), and to the blaming of those who resist or are unable to subscribe to such diets or advice. Sociological research has highlighted the disconnection that exists between the healthy eating guidelines of health promotion in wider media and citizens' everyday lived experiences (Lindsay, 2010). Recent sociological research on food has been greatly influenced by the growing risk literature from the early 1990s, following the publication of Beck's influential 'risk society' thesis in 1992. For example, the journal, Health, Risk and Society, has published numerous articles on food and risk from the 1990s, including analyses of such topics as media reporting of food risks, dietary risks, and consumer perspectives on food risk management. Growing interest in critical public health issues from the early-to-mid 1990s, largely inspired by the new sociological theories of risk, also focused attention on the surveillance and governance implications of advice on diet and health (e.g. Petersen and Lupton, 1996).

The surveillance (including self-surveillance) implications of public health and health promotion strategies and wider media portrayals of dietary risk, including obesity and eating disorders, has been the focus of considerable work over the last two decades (e.g. Gard and Wright, 2005; Nasser, 1997; Nasser et al., 2002). It is here that the work of Foucault and his concept of governmentality has proved especially useful, in understanding the governance implications of the increasing surveillance, and the 'responsibilisation' (O’Malley, 2009) associated with neoliberal risk discourses, such as those pertaining to obesity and healthy diets (Petersen e. al., 2014; Warin, 2011). Governmentality, defined as 'the conduct of conduct' (Gordon, 1991 p. 2), pays attention to the rationalities of power and the ways in which citizens' self governance, for example in relation to the monitoring and management of one's own and/or families' diets, is linked to broader sociopolitical objectives. Within this framework, the concept of choice, which implies unconstrained action, is problematised. For example, what appears to be a domain of unconstrained choice, about food items and diets, is shown to link to a broader analytics of power. Thus, 'healthy 
eating practices' and engagement in anti-obesity measures and preventive, risk management practices, can be seen as part of a broader workings of power whereby citizens are made responsible for actions once undertaken by the state or which previously were not perceived as issues for action (see Cronin et al., 2014).

Analyses of historical discourses serve to reveal the power relations associated with shifting discourses of food, diet/ing, and ideal weight, and related practices. Such an analysis proved useful in a recent study of 'superfoods', for example, in highlighting the moral and governmental implications of the marketing of these 'superfoods' which were advertised as 'anti-ageing' products in a context of 'gastro-anomy' (Fischler, 1980) during a period of growing normlessness regarding food (MacGregor et al., 2018). As this and other studies of the media highlight, sociological analyses can serve to unsettle taken-for-granted ways of knowing, showing them to be historically contingent and inextricably linked to the workings of power, and thus contestable and changeable. Moreover, images of families portrayed in advertising and commercial media come to shape how we think about the family and interpret family life (Davis et al., 2016; Leiss et al., 2005; Goffman 1979; Heaphy, 2011). With the growing influence of newer, digital media, including citizens' use of self-tracking devices, blogs and social media that enable them to generate their own stories, and in some cases serve as de facto marketers, and advertisers' growing use of personalised algorithms to promote products, the need for critical perspectives on the discourses of food and diet has never been greater (Schneider et al., 2018).

\section{The Family as a socio-cultural site of economic significance}

The family, Bourdieu (1996) argues, is conceived as a kind of notional collective personae - the individual traits of its members all fused into one collective profile. This notional family resides within a 'sanctum' of domestication and a 'moral' domain (Chambers, 2001) where decisions are made to consume, and to participate in the economic sphere which lies outside the sanctum of the 
domestic threshold. Bourdieu (1996) goes as far as to call this notional family imagined by most societies as 'a well-founded fiction' (1996, p.20). Why this 'well founded fiction' of the 'functional nuclear family' is important for most liberal capitalist societies, is explained by Bourdieu as being one of 'the key sites for the accumulation of capital in its different forms'. This is echoed by Chambers (2001p.49) when she suggests that this emphasis on the nuclear family as a key social unit began to gain most prominence in the post war industrial/ consumer society of the $1950 \mathrm{~s}$. Chambers suggests that Talcott Parsons and sociologists of the era elevated the idea of the "white nuclear family' (Chambers, 2001, p. 49) as the basis for a new functional model on which modern societies would be built. In the new socio-economic model, nuclear families were mobile, had internally strong affective ties that made them cohesive, but had no kinship obligations beyond 'parents and dependent children' and could be used to drive the new industrial work and consumption of new goods that the era of prosperity brought in this period. All state level planning henceforth would happen on the basis of the 'household' defined as the parents and dependent children. This conceptual idea of the small independent family unit had profound implications for the mobility of a labour market, for the suburban spread of housing construction, and for the infrastructure that came to facilitate the suburbs through automobile ownership... all built for the 'normal' nuclear family. In brief Chambers (2001, p. 50) suggests 'Parsons invented a model of the family that would fit neatly the labour needs of post war American society'. Making this notion of the family a living breathing 'real' social phenomenon takes work; this work is often emotional labour or caring work that mostly women engage in. Here it may be worthwhile mentioning Finch's (2007) work on why 'display' of family is important. Her work is a rare example of where the links between individual 'practices' (Morgan, 1996) of family are manifested and connected to the display of the collective notion of family which derives its meaning from the larger context of societal norming. Thus, family practices (the 'little fragments daily life' Morgan, 1996;190) such as feeding and family meals are a key part of the display of 'familyness' (Chambers, 2001) and help to constantly sustain the emotional reinforcement of the idea of the nuclear family. Moreover, the 
mundane consumption practice of the meal features prominently in the debates around family and food and reveals much about the routinized organization of family eating (Yates and Warde, 2017; Jackson, Olive and Smith, 2009; Marshall, 2005, 2018) with implications for family health and well-being (Fulkerson et al., 2009; Larson et al., 2013; Burgess-Champoux et al., 2009). Finch suggests that display is particularly, and often even more urgent, in times where the idea of family is constantly being redefined. This fluidity calls for constant display and performance to convey to others that the individual 'family' is socially functional. In addition, Finch emphasizes that individuals within this family group change, children grow up, adults move in and out of employment and age. At each of these points in time the everyday practices change, thus the relational ties have to be reinforced sometimes by changed everyday practices, hence these new 'familial practices' need to be displayed and are 'seen' to be legitimized/affirmed by others in the social context. Much of this work lies in nurturing of the family and around food. We discuss this in more detail below.

Along with the social construction of the nuclear family as facilitating the labour market, came the notion of the family as a 'consumption' unit. Here the interests of the commercial and 'free' market dovetails with that of the state (Cook, 1995). While the 'commodity frontier' (Hochschild, 2004) was still some way off from being identified and crossed, the way markets were shaping both how families consumed and behaved as a family was becoming clear (see Julier, 2016). Zelizer (2005) argued that 'feeding the family provides an obvious yet forgotten intersection of caring and economic activity" (p.163).

Building on this Lindsay and Maher (2013) emphasise that food production and consumption within the familial context, while inevitably an economic activity, serves to enact familial relationships of caring and nurturing on an everyday basis (p.10). However, they point to the inherent contradictions and tensions that the family consuming as a collective comes up against in the inherently 
individualised capitalist system. These paradoxes or 'antinomies of consumption' in food are delineated by Warde (1997), and linked closely to 'culinary taste' or distinction. These paradoxes or antinomies are often resolved for the consuming family by the marketplace.... 'Economic YET Luxurious'; 'home-cooked taste, BUT ready in minutes!' (Schneider and Davis, 2010; Julier, 2016; Jackson, 2018).

Managing the family and its consumption, whether on how to feed children or how much to eat, has often been recommended by the public health authorities through a series of public health measures. Increasingly, however, these forms of regulation have shifted from the direct regulation of what food is produced and marketed (and how it is marketed) to a prevailing environment of families and individuals being responsibilised for their own health and food consumption; including governance of family meals (see Hiroko, 2009). The healthy body is an imperative in late capitalist neoliberal societies, but the ways in which this imperative is deployed has changed somewhat. In the 20th century public health measures we saw prescriptive rules about how germs were to be kept at bay and eating to keep the body 'fighting' fit (Warin, 2011), today the imperative is to stay healthy in order to be economically useful (healthy worker) and to be able to continue to be a good consumer of what is produced by the market.

\section{The State, 'Red Herrings' and 'let's blame the mothers'}

Thus, the problematizing of the family (childhood obesity and by extension the mother) means that the responsibility for the healthy body shifts. It is no longer a problem that governments should tackle by making healthy food cheaper or more accessible to the population. Coveney (2008) suggests that governments and private interests frame this 'problem' as one that needs to be tackled at the family or individual level. In effect this then works as a shifting of the weight of responsibility away from two groups that would traditionally be the sites of public health solutions: 
governments (in the form of food marketing regulation); and the food industry (quality, reformulation, price and accessibility). Instead, the individualisation discourse creates a convenient 'red herring' in this debate as health becomes a matter of 'choice' and the individual responsibility of parents (mothers in particular) within the family.

As Warin (2011) points out this framing of the mothers as well as the increasing sense of 'selfregulation' via reality TV and an arsenal of 'cultural technology' - serves to absolve the state or the food industry of blame in the creation of the obese child. It takes away the focus from the structural disadvantages of class, race or education that may prevent access to, and the consumption of, healthy food. Focusing on individual or family education and upskilling in food preparation, conveniently ignores the deeply entrenched food disadvantages that the poor experience. These disadvantages are created in part by neoliberal governments (let the market decide/no nanny state) and in part by big food (price, profit and demand) that drive production and availability. Most importantly this framing absolves governments (lobbied by the powerful food industry) from introducing unpopular regulatory measures around making more fresh produce cheaply and easily available or making processed or HFSS (High Fat Sugar and Salt) foods more expensive, although recent health initiatives have centered, for example, on pricing measures related to soft drinks and, in Scotland, minimum pricing for alcohol (Triggle, 2018). Food, as we have seen, is inherently political (Mann, 2017; Laing 2015) and feeding the family is often a moral, ethical, social and emotional process (De Vault, 1991; Pollan, 2013.) This then makes the family a site of food socialisation and a key focal point from which to examine how identity, sociality and the playing out of relational practices come to be. Critically examining this politically significant and culturally key site may help us see whether or not Pollan's declaration that "The shared meal is no small thing. It is a foundation of family life, the place where our children learn the art of conversation and acquire the habits of civilization" (Pollan,, 2013 p.9) is overstated and if it is indeed the individual 
responsibility of the parent (mother) to make this civilizing ritual moment happen? This leads to another key aspect of family and food notably the gendered nature of caring for the family.

\section{Mothering responsibilities for social caring connections: food in family life}

As McMahon notes in Engendering motherhood: Identity and self-transformation in Women's Lives, 'The value of caring and supportive human relationships and the work that women do in producing and holding up the social world of caring connections.... this is what motherhood symbolizes". (McMahon, 1995 p.vi). Mothering tends to fall largely, but not entirely, on women. Both mothers and fathers are involved in what Daniel Miller (1998) described as the labour of love in many of the mundane tasks of family life. However, this rightfully careful acknowledgement of men's role in feeding the family aside, what comes through in many discourses - in popular policy, feminist and academic debates and across various cultural contexts - is the view that the primary responsibility for the dual roles of 'caring for' (Parker cited from Ungerson 1983 in De Vault 1991, p. 239) and 'caring about' (Finch and Groves, 1983; Waerness, 1984; Abel and Nelson, 1990), largely fall on women as mothers. McMahon identifies the conundrum as follows from her study of new mothers in Canada, "The greatest rewards of being a mother came from the special connectedness these women felt with their children and from the pleasure of watching their children learn and grow. However, the flip side of feeling connected - feeling responsible - was seen as one of the worst things about being a mother" (McMahon, 1995 p. 268).

Juggling responsibilities and activities is central to mothers' experiences of family life (as shown in Thompson's (1996) study of U.S. mothers). Feeding the family remains a central concern as it involves the production and maintenance of family life. As McMahon indicates above, the social world of caring connections is central to women's work within the family. Feeding the family - all the forms of provisioning involved and the associated tasks (e.g. writing shopping lists that cater for 
everyone's tastes; working within the budget; planning menus that accommodate the preferences and activities of all family members (e.g. Molander's study of single Swedish mothers, 2011, 2017); shopping (e.g. Miller's study of London families, 1998); ensuring healthy diets for the family; preparing the dishes - whether from scratch or otherwise - feeding the family involves significant levels of labour and links with McMahon's (1995) view above about how the social world of caring connections is closely associated with the production of sociability as noted by De Vault (1991) in her Chicago study of feeding the family.

But we are really jumping a little ahead of ourselves here. We can trace women's responsibilities for their children's health in the context of food and diet to well before the picture of busy family lives painted above. Women are exhorted by public policy and medical discourses before pregnancy to watch their diet carefully (nutrition.org) to help improve their chances of conceiving; or to protect the very early stages of foetal development before the pregnancy is clearly established. During pregnancy expectant mothers are offered guidelines around what and what not to eat to ensure that their foetus grows healthily in the womb (NHS choices, 2018; medilineplus.gov, 2018), and is not threatened by any adverse effects of their mothers' diet e.g. that nothing untoward crosses the placenta as illustrated by a study of pregnant Korean women (Jeong et al., 2018). Expectant mothers are also monitored for weight gain, as obesity in pregnancy is under scrutiny because of the potential short-term and longer-term effects for both mothers and children as shown by a study of expectant Egyptian mothers at a Cairo hospital (Abdel-Aziz et al., 2018).

Once the new baby arrives, then all the debates about child care and upbringing begin, with the discussion of infant feeding at the forefront (with issues of sleeping patterns sometimes linked to feeding decisions). The World Health Organization is just one of the protagonists in arguing for the advantages of breastfeeding which is pressed on the new, excited but often very weary, new mother (WHO, 2016). Alongside the breastfeeding arguments are the counter-arguments for or against 
other choices (such as bottle feeding; supplementing breast milk with bottle feeding; or moving to mixed feeding too early). These arguments are the source of many advice sheets for new mothers. Murphy $(1999 ; 2000)$ provides an interesting analysis of U.K. mothers' choices around infant feeding from a Foucauldian perspective. A more recent U.K. study illustrates the range of alternative, potentially conflicting, discourses which new mothers face in their local maternal cultures. This study showed the variety of discourses drawn on by new working-class English mothers and argues that infant feeding decisions fit into a range of other choices that young working-class women face as new mothers (Banister and Hogg, 2018). Their findings show how these young women seek to negotiate a variety of societal discourses not just about infant feeding, but about keeping the family together and relationships going - relationships which potentially face significant challenges in the face of lack of sleep and disturbed routines. This is another facet of McMahon's (1995) opening point that links feeding and caring to the wider issues of social connections and family life.

As the children grow, parents' responsibilities for encouraging sensible and healthy eating, balanced diets; and healthy lifestyles that combine sensible food choices with exercise - remain at the forefront of popular and policy messages to parents (as Moore, 2018 points out). Academic researchers produce evidence to support these popular policy arguments and mothers are the main audience for many of these messages. Families and food involve a careful consideration of meal planning; healthy diets; management of sugar and fizzy drinks in children's lunch boxes (Allison, 1991; Cappellini and Harman, 2015) along with the range of individuals' activities and schedules which affect the planning and provisioning of family life (De Vault, 1991; Cappellini et al., 2016; Moore, Wilkie and Desrochers, 2016). Echoing De Vault's (1991) point about how feeding the family involves a whole range of tasks and routines, a recent U.S. study of low income employed mothers examined how work and family pressures affected parents' daily routines for feeding their young children. They found that "mothers' feeding routines were distinguished by a combination of 
four recurring key strategies - planning ahead, delegating, making trade-offs, and coordinating..." (and).... "understanding how young children are fed requires recognizing the socio-ecological environments that involve working mothers' daily schedules and household conditions and the multiple ways that mothers manage food and feeding to fit environmental constraints. There is a need to look at more than just family meals to understand parents' daily strategies for feeding young children and their implications for child nutrition" (Agrawal et al., 2018 p.57).

As the children leave home women are faced with empty nests. Doing motherhood and doing family takes on a different shape (Hogg et al., 2004). The site for doing family changes from a fairly physically constrained household to a set of dispersed sites for generating the maintenance of a sense of family (if not of family life in the sense of time and activities shared e.g. meal times). Mothering and motherhood has to be learnt anew/afresh. Family relationships necessarily need to change (e.g. from parent-child to adult-adult). Women continue their mothering role but are often faced with feelings of grief and loss (Bowlby and Parkes, 1970; Worden, 1991) as they learn to negotiate the changing tasks associated with motherhood (Curasi et al., 2013).

It would seem that the responsibilities for feeding their children would start to diminish at the empty nest stage - and indeed the direct responsibilities for feeding the family do diminish, in the sense of the lessening need to produce a physical meal on the table at the end of the working day for the families' evening meal. However, at the same time, it is possible to see a shift from the actual task of feeding the children, to helping the children feed themselves e.g. using skype, social media and other means to share experiences of cooking favourite dishes as children pick up the essential food preparation skills necessary for looking after themselves independently (e.g. Gram et al., 2015). 
Finally, revisiting McMahon's (1995 p.276) proviso above, and picking up on De Vault's point: "Motherhood is not a "woman's issue" both because men, too, can (and do) care and perform family work and because it raises broader questions about the nature of social bonds and social responsibility" - not least in terms of feeding the family. In the next section we turn to a relatively unexplored aspect of gendered responsibility, the role of fathers.

\section{Shifting fathering responsibilities from cash to care}

As Blakenhorn observes "Historically, the good father protects his family, provides for its material needs, devotes himself to the education of his children, and represents his family's interest in the larger world." (Blankenhorn, 1995 p.122). The provision of material needs is best captured in the idea of the 'breadwinner', a role traditionally attributed to the male head of the household and closely aligned with being a 'good' father. The 'breadwinner', literally, identifies the father as the one providing the 'dough' (father/provider) to make the 'bread' (mother/carer). This notion of the male breadwinner can be traced back to the Industrial Revolution and a shift from the rural to the urban and from producer to consumer society; men went out to work while women stayed at home and looked after the family (Lewis, 2000; Lamb, 2000; Russell, 1986). However, as Brannen and Nilsen note 'In earlier generations, fatherhood was typically defined in terms of being a sole or main breadwinner. Within this model, men used paid work to exempt themselves from childcare, at least in children's early years. This was the case especially for the older generations in the study. Sole breadwinning is absent in the current generation, representing significant change in the institution of fatherhood. It is also a cultural change since breadwinning is no longer seen to legitimize a form of fathering whereby men are exempt from active involvement with children' (2014 p. 348).

Today, around seventy six percent of British men (16-64) and sixty seven percent of British women (16-64) are in full time employment (twelve percent of men and forty two percent of women are employed part time) with sixty eight percent of households classified as dual earner (ONS, 2013). In couple families the percentage of both parents working full time has increased 
from just over a quarter to almost one third (Modern Parenthood, 2016). So, while the male breadwinner model is not by any means extinct there are questions around its ubiquity, for example, the growth in dual earning households often means that households are trying to co-ordinate work schedules, with some fathers taking more responsibility for childcare provision including shopping and preparing food for the family (Miller, 2017). Consequently, we are seeing new forms of fathering and emerging 'narratives of fatherhood', with an emphasis on 'caring' and 'being there' which suggests a 'detraditionalisation of fatherhood' that alludes towards more gender equality in relation to childcare and the family (Wall and Arnold, 2007). Importantly, men's involvement in childcare is much more visible and for some men very different from the experiences of their own fathers (Miller, 2011). In moving away from the breadwinner model and hegemonic masculinity we are witnessing an increasing diversity of fatherhood types, that includes fathers who are caring, compassionate and nurturing (Miller, 2017; Marshall et al., 2014). This is important because the debate about responsibilisation (re)positions fathers more centrally in relation to family care. Yet, as boundaries between work and family life become increasingly blurred and family roles more fluid (Olah, 2013), income differentials have not helped in advancing gender equality. It is not that fathers do not care, or are not capable of caring, rather a trade-off exists between this and their need to provide, particularly given their earning potential in the labour market (Dermott and Miller, 2015). Once again, we see the impact of broader social and political changes on the family unit.

As discussed in the previous section, we tend to view family consumption through the maternal lens - for example, food shopping is traditionally the responsibility of mothers - but calls for greater involvement of fathers in domestic care activities are countered with arguments around maternal gatekeeping and the need to protect domestic spaces from male engagement (Gentry et al., 2003). This is not helped by the depiction, until fairly recently, of fathers (in advertising) as incompetent and relegated to secondary caregiver roles (La Rossa, 1997; La Rossa et al., 2000; Wall and Arnould, 2007). However, despite greater engagement and a willingness to get involved in 
childcare, especially among new fathers, the realities of the labour market prevail and the bulk of the mental work of responsibility continues to fall on mothers (Miller, 2017). While much of the feminist debate has centered on women's rights to pursue goals outside of the home we have much less debate about fathers' rights to spend more time with their children, something partially addressed in recent legislation on shared parental leave. The change in policy approaches in the U.K. for example, to support these new directions in family life can be seen in the recent initiatives on shared parental leave (Kerrane and Banister, 2017). Fathers' involvement in child rearing is becoming increasingly important because early paternal involvement can be very beneficial, indicating greater likelihood of longer term involvement (Norman, et al., 2014).

To be a good dad, is not just about, or even about, being a breadwinner but about investing in family time with partners and children. As Miller (2017) argues in Making Sense of Parenthood: Caring Gender and Family Lives the modern 'involved' father is taking care of the kids, particularly among young fathers in the early years of parenting, but their 'caring practices do not mirror those of women in exact ways, nor do they carry the same burden of caring' (2017 p. 74). Fathers are engaging in a new language of caring, bonding and connecting emotionally with their children - not just providing financially (Miller, 2011). Consequently, this shifts our ideas about fatherhood. This can be seen in the case of stay-at-home dads (Coskuner-Balli and Thompson, 2013) and single dads (Harrison et al., 2012; Molander, 2017) who undertake domestic responsibilities for family life, including feeding their families. Molander (2018) found that single fathers in Sweden retained their professional identity and were not stigmatised by domestic work in the same way as Coskuner-Balli and Thompson's stay at home dads, who had lost their breadwinner identity (although the fathers in their US sample did see meal preparation as part of 'masculinizing domesticity'). For these Swedish fathers cooking and eating dinner with their children was an important part of parenting. They were relaxed about turning to the market for ready-made solutions when required, while striving to provide nourishing food for their children, as 
Molander (2018) notes, 'convenience did not lead to less care'. Yet we know relatively little about the often neglected, silent, mainstream, of fathers in couple households and how they adjust and juggle their own work-life balance to spend more time with the family. Are contemporary fathers cooking meals, making up children's school lunchboxes, and doing the shopping? There is also a question around whether equality and equity is actually achievable, given that mothers still undertake the majority of childcare, but equally there may be caring tasks and certain aspects of consumption related behaviour that remains gendered. Szabo (2014) talks about 'traditional culinary masculinities' in which cooking is associated with leisure, culinary performance, or practical skills in contrast to 'traditional culinary femininities' centered on love and care. Food is one aspect of consumption where fathers are most likely to make a contribution to family care activities both directly in doing the food shopping, preparation or cooking and indirectly in making time to spend with the family over food around the table, the barbecue or at the restaurant (Szabo, 2013, 2014; Meah, 2017).

Finally, cultural representations in popular media and marketing can contribute to how we perceive fathers and in the pages of popular media fathers have been shown, more often than not, outside of the home and away from the kitchen in very traditional male roles, while mothers dominate the private domestic space reinforcing the idea of food and family care as women's work (Gentry and Harrison, 2010; Davis et al., 2016). Where fathers do feature in family related advertising they tend to be shown playing with their children rather than necessarily attending to the care of their children, and somewhat less involved in the kitchen (Marshall et al., 2014; Wall and Arnold, 2007). How much this reflects the realities of contemporary family life is unclear but fathers may be much more engaged in family food related activities than the advertisers or companies are prepared to acknowledge. The mother as gatekeeper model remains a key part of how we think about families but we still have a lot to learn about how men, and fathers, engage in family food practices. 
In summary we argue that any consideration of family and food needs to consider the social, cultural, economic and political context of family food choice. As the responsibilization for food (and health) shifts from the state to the family our consumption practices are increasingly influenced by the market, informed by the media and shaped by our food experiences, many of which reside in mundane aspects of family feeding and the associated provisioning tasks. While we cannot, and should not, ignore the material and nutritional aspects of food, social and cultural aspects of eating continue to shape how we think about food. Much family food work remains highly gendered but there is evidence of something of a shift, albeit small, in the shared responsibilities for food and feeding the family. Food can tell us much about the nature of contemporary family life and in that sense, there are many more stories still to be told about families and food. Let us hear some of them.

\section{References}

Abdel-Aziz, S. B., Hegazy, I.S., Mohamed, D.A., Abu EL Kasem, M.M.A., and Hagag, S.S. (2018), "Effect of dietary counseling on preventing excessive weight gain during pregnancy" Public Health Vol 154 pp. 172-181.

Abel, E. K. and Nelson, M. K. (Eds.) (1990), Circles of care. State University of New York, Albany. (cited in De Vault 1991 op. cit.)

Agrawal T., Farrell, T.J., Wethington, E., Devine, C. M. (2018), “'Doing our best to keep a routine': How low-income mothers manage child feeding with unpredictable work and family schedules" Appetite Vol 120 pp. 57-66 https://doi.org/10.1016/j.appet.2017.08.010 (Accessed $1 / 02 / 18)$

Akerloff, G. A. and Shiller, R. J. (2015), Phishing for Phools: The Economics of Manipulation and Deception. Princeton University Press: Princeton and Oxford. 
Allison, A. (1991)," Japanese mothers and obentōs: The lunch-box as ideological state apparatus”. Anthropological Quarterly Vol. 64 No. 4, pp. 195-208.

Banister, E. N. and Hogg M.K. (2018), 'Infant feeding as a dividing practice? Young mothers' rhetorical strategies around infant feeding discourses". Unpublished working paper

Beck, U. (1992), Risk Society: Towards a new modernity, Sage Publications, London.

Bellamy, J.B. (2016), "Marx as a food theorist”, Monthly Review, Vol. 68 No. 7,

https://monthlyreview.org/2016/12/01/marx-as-a-food-theorist/ (Accessed 9/06/2018).

Blankenhorn, D. (1995), Fatherless America: Confronting Our Most Urgent Social Problem. Basic

Books, New York.

Bourdieu, P. (1996), “On the Family as a Realized Category”, Theory Culture Society, Vol. 13 pp. $19-26$.

Bowlby, J. and Parkes, C. M. (1970), 'Separation and loss within the family,' in Anthony, E.J. and Koupermil C.M. (Eds), The Child in this Family, Wiley, New York.

Brannen, J. and Nilsen, A. (2006), "From fatherhood to fathering: Transmission and change among fathers in four generation families", Sociology, Vol. 40 No. 2, pp. 335-352.

Burgess-Champoux, T. L., Larson, N., Neumark-Sztainer, D., Hannan, P. J., and Story, M.

(2009), "Are family meal patterns associated with overall diet quality during the transition from early to middle adolescence?" Journal of Nutrition Education and Behavior, Vol. 41 pp. 9-86.

Cappellini B. and Harman V. (2015), "Mothers on Display: Lunchboxes, Social Class and Moral Accountability", Sociology, Vol. 49 Vo. 4, pp. $764-78$.

Chambers, D. (2001), Representing the Family, Sage, London.

Cook, D. T. (1995), “The Mother as Consumer: Insights from the Children's Wear Industry, 19171929”, The Sociological Quarterly, Vol. 36 No. 3, pp. 505-522. 
Coskuner-Balli, G. and Thompson, C.J. (2013), “The Status Costs of Subordinate Cultural Capital: At-Home Fathers' Collective Pursuit of Cultural Legitimacy through Capitalizing Consumption Practices”, Journal of Consumer Research, Vol. 40 No. June, pp. 19-41.

Coveney, J. (2008), “The government of girth”, Health Sociology Review, Vol 17 No. 2, pp.199213.

Curasi, C. F., Maclaran, P. and Hogg, M.K. (2013), "Mothers and their empty nests: employing consumption practices to negotiate a major life transition" in O’Donohoe, S., Hogg, M., Maclaran, P., Martens, L., and Stevens, L. (Eds) “Motherhood, markets and consumption: the making of mothers in contemporary Western cultures", Routledge, London, pp. 171-182.

Davis, T., Marshall, D., Hogg, M., Schneider, T. and Alan Petersen, (2016), 'Consuming the Family and the Meal: Representations of the family meal in Women's Magazines over 60 years'. In Cappellini, B., Marshall, D. and Parsons, E. (Eds.) 'The Practice of the Meal: Food, families and the marketplace, Routledge, Oxon, pp. 137-150.

Cronin, J., McCarthy, M., Brennan, M. and McCarthy, S. (2014), “The bigger society: considering lived consumption experiences in managing social change around obesity", European Journal of Marketing, Vol. 48, Nos 9/10, pp. 1558-1578.

Dermott, E. and Miller, T. (2015), "More than the sum of its parts? Contemporary fatherhood policy, practice and discourse", Families, Relationships and Societies, Vol. 4 No. 5, pp. 183-195. DeVault, M. L. (1991), Feeding the Family: The Social Organization of Caring and Gendered Work. The University of Chicago Press: Chicago and London.

Doyal, L. with Pennell, I. (1979), The Political Economy of Health. Pluto Press: London. Finch, J. (2007), “Displaying Families”, Sociology, Vol. 41 No. 1, pp. 65-81. DOI: $10.1177 / 0038038507072284$

Finch, J. and Groves D. (1983) Eds. A Labour of Love: Women, Work and Caring Routledge, Kegan and Paul, London. 
Fischler, C. (1980), "Food habits, social change and the nature/culture dilemma", Social Science Information, Vol. 19 No. 600 pp. 937-953.

Foxcroft, L. (2011), Calories and Corsets: A History of Dieting Over 2,000 Years. Profile Books Ltd: London.

Fulkerson, J. A., Kubik, M. Y., Story, M., Lytle, L., \& Arcan, C. (2009), “Are there nutritional and other benefits associated with family meals among at-risk youth?”, Journal of Adolescent Health, Vol. 45 No. 4, pp. 389-395. Available at http://doi.org/10.1016/j.jadohealth.2009.02. (Accessed 23/05/18).

Gard, M. and Wright, J. (2005), The Obesity Epidemic: Science, Morality and Ideology. Routledge, London.

Gentry, J., Commuri, S. and Jun, S. (2003), "Review of literature on gender in the family”, Academy of Marketing Science Review, Vol. 1 pp. 1-18.

Gentry, J. and Harrison, R. (2010), "Is advertising a barrier to male movement towards gender change?" Marketing Theory, Vol. 10 No. 1, pp. 74-96.

Goffman, E. (1979), Gender Advertisements, Harper Row, New York.

Gordon, C. (1991), “Governmental rationality: an introduction”, in Burchell, G., Gordon C. and Miller P. (Eds.) The Foucault Effect: Studies in Governmentality. Harvester Wheatsheaf, London. Gram, M., Hogg, M.K., Blichfeldt, B.S. and Maclaran, P. (2015), “Intergenerational Relationships and Food Consumption: The stories of young adults leaving home", Young Consumers, Vol. 16 No. 1, pp. 71 - 84. http://dx.doi.org/10.1108/YC-01-2014-00422.

Harrison, R., Gentry, J. and Commuri, S. (2012), "Gender Role Transition to Involved Parenting: The Role of Household Production and Consumption in the Lives of Single Fathers", Otnes, C. and Zayer, L.(Eds.) Gender, Culture and Consumer Behavior, Routledge, New York, pp. 337-369. Heaphy, B, (2011), “Critical Relational Displays", in Dermott E. and Seymour, J. (Eds.) Displaying Families: A New Concept for the Sociology of Family Life, Palgrave MacMillan, Basingstoke, pp. 19-37. 
Hier, S. P. (2008), “Thinking beyond moral panic: risk, responsibility, and the politics of moralization”, Theoretical Criminology, Vol. 12 No. 2, pp. 173-190.

Hiro, T. (2009), “The governing of family meals in the UK and Japan”, in Jackson, P. (Ed.) Changing Families, Changing Food. Palgrave Macmillan, Basingstoke, pp. 165-184.

Hochschild A.R. (2004), “The Commodity Frontier” in Alexander, J., Marx, G. and Williams, (Eds.) Self, Social Structure and Beliefs: Essays in Sociology, University of California Press, Berkeley.

Hochschild, A R. 1(983/2012), The Managed Heart: Commercialization of Human Feeling. London: University of California Press, Berkeley.

Hogg, M.K., Curasi, C.F. and Maclaran P. (2004), “The (re)-configuration of production and consumption in empty nest households/families" Consumption, Markets and Culture, Vol. 7 No. 3 , pp. 239-259.

Jackson, P., Olive, S and Smith, G. (2009), "Myths of the family meal: Re-reading Edwardian life histories" in Jackson, P. (Ed.) Changing Families, Changing Food, Palgrave Macmillan, London, pp. 129-130.

Jackson, P. (2015), Anxious Appetites: Food and Consumer Culture, Bloomsbury Publishing, London.

Jackson, P. (2018), "Familial fictions: families and food, convenience and card” European Journal of Marketing Special Issue Families and Food: Marketing, Consuming and Managing. Jackson, P. and Everts, J. (2010), “Anxiety as social practice”, Environment and Planning A, Vol. 42 pp. 2791-2806.

Jeong, Y., Lee, S., Kim, S., Park, J., Kim, H-J., Choi, G. et al. (2018), "Placental transfer of persistent organic pollutants and feasibility using the placenta as a non-invasive biomonitoring matrix" Science of the Total Environment Vol. 612 No. 15 January pp. 1498-1505. https://doi.org/10.1016/j.scitotenv.2017.07.054. 
Julier, A. (2016), “Appropriation”, in Cappellini, B., Marshall, D. and E. Parsons (Eds.)

'The Practice of the Meal: Food, families and the marketplace', Routledge, Oxon, pp. 77-

91.

Kerrane, B. and Banister, E. (2017), “Cultural hindrances to 'involved fathering' in the context of SPL [Shared Parental Leave]" in British Sociological Association Conference, 2017-04-042017-0406, Manchester University.

Lang, T.M. (2015), Food Wars: the Global Battle for Mouths, Minds and Markets. Routledge, Abingdon. ISBN 978-1-138-80262-9.

Lamb, M. E. (2000), “The history of research on father involvement: An overview”, Marriage \& Family Review, Vol. 29 pp. 23-42.

La Rossa, R. (1988), “Fatherhood and social change”, Family Relations, Vol. 37 pp.451-457.

La Rossa, R. (1997), The modernization of fatherhood: A social and political history. University of Chicago Press, Chicago.

Larson, N., MacLehose, R., Fulkerson, J. A., Berge, J. M., Story, M., \& Neumark-Sztainer, D. (2013), "Eating breakfast and dinner together as a family: Associations with sociodemographic characteristics and implications for diet quality and weight status", Journal of the Academy of Nutrition and Dietetics, Vol. 113 No. 12, pp. 1601-1609. http://doi.org/10.1016/j.jand.2013.08.011. Leiss, W., Kline, S., Jhally, S. and Botterill. J. (2005), Social Communication in Advertising: Consumption in the mediated Marketplace, $3^{\text {rd }}$. edition. Routledge, New York and Oxon. Levenstein, H. (2012), Fear of Food: A History of Why We Worry about What We Eat. The University of Chicago Press, Chicago and London.

Lewis, C. (2000,) A man's place is in the home: Fathers and families in the UK. Joseph Rowntree Foundation, York, Available at https://www.jrf.org.uk/report/mans-place-home-fathers-andfamilies-uk (accessed 19/05/18).

Lindsay, J. (2010), 'Healthy living guidelines and the disconnect with everyday life', Critical Public Health, Vol. 20 No. 10 pp. 391-400. 
Lindsay, J. M., and Maher, J. M. (2013), Consuming Families: Buying, Making, Producing Family Life in the 21st Century, Routledge, New York, USA.

MacGregor, C., Petersen, A. and Parker, C. (2018), 'Promoting a healthier, younger you: the media marketing of anti-ageing superfoods", Journal of Consumer Culture. In Press available at http://journals.sagepub.com/doi/full/10.1177/1469540518773825 (accessed 23/05/2018).

McMahon, M. (1995), Engendering motherhood: Identity and self-transformation in Women's Lives, The Guilford Press, New York.

Mann, A. (2017), "Hashtag Activism and the Right to Food in Australia”, in Schneider, T., Eli, K., Dolan, C. and Ulijaszek S. (Eds.), Digital Food Activism, Routledge, London.

Marshall, D. (2018), "Feeding in context: eating occasions as domestic socialized practice”, in Harman, V., Cappellini B. and Fairclough C. (Eds.), Feeding Children Inside and Outside the Home: Critical Perspectives. Routledge, London.

Marshall. D. (2005), “Food as Ritual, Routine or Convention?”, Culture, Markets and Consumption, Vol. 8 No. 1 pp. 69-85.

Marshall, D. (2018), "Feeding in context: eating occasions as domestic socialized practice", in Harman, V., Cappellini B. and Fairclough C. (Eds.), Feeding Children Inside and Outside the Home: Critical Perspectives. Routledge, London.

Marshall, D., Davis, T., Hogg, M., Petersen, A. and Schneider, T. (2014), “From overt provider to invisible presence: discursive shifts in advertising portrayals of the father in Good Housekeeping, 1950-2010”, Journal of Marketing Management, Vol. 30 Nos.15-16, pp. 1654-1679.

Meah, A. (2017), "Fathers, food practices and the circuits of intimacy in families in Northern England", Gender, Place and Culture, Vol. 24 No. 8 pp. 1145-1165. medilineplus.gov (2018) Pregnancy and Nutrition. Available at https://medlineplus.gov/pregnancyandnutrition.html (accessed 23/05/18).

Miller, D. (1998), A Theory of Shopping. Polity Press/Cornell University Press, Cambridge. Miller, T. (2011), Making Sense offatherhood. Cambridge University Press. Cambridge. 
Miller, T. (2017), Making Sense of Parenthood: Caring, Gender and Family Lives, Cambridge University Press. Cambridge.

Mills, C. W. (2000; orig. 1959), The Sociological Imagination. Oxford University Press: Oxford. modernfatherhood.org (2016), "Parental Working in Europe: Household patterns of work" http://www.modernfatherhood.org/wp-content/uploads/2016/03/Parental-Working-in-EuropeHousehold-Patterns-of-Work-final_formatv3.pdf. Cited in The Modern Families Index (2017) available at https://www.workingfamilies.org.uk/wp-content/uploads/2017/01/Modern-FamiliesIndex_Full-Report.pdf (accessed 23/05/18).

Molander, S. (2011), “Food, Love and Meta-Practices: A Study of Everyday Dinner Consumption Among Single Mothers”, In Belk, R.J.W, Grayson, K., Muñiz, A.M., Schau H.J. (Eds.) Research in Consumer Behavior (Research in Consumer Behavior, Volume 13 Emerald Group Publishing Limited, Bingley, Yorks, pp.77 - 92.

Molander, S. (2017), "Not just a mother: embodied and positional aspects of consumer learning from a practice perspective", Consumption, Markets and Culture, Vol. 20 No. 2, pp. 131-152. https://doi.org/10.1080/10253866.2016.1193014.

Molander, S. (2018), "Swedish Fathers Feeding the family”, in Harman, V., Cappellini B. and Fairclough C. (Eds.), Feeding Children Inside and Outside the Home: Critical Perspectives. Routledge, London.

Moore, E.S. (2018), “Intergenerational influences on children's food preferences and eating styles; a review and call for research", European Journal of Marketing Special Issue Families and Food: Marketing, Consuming and Managing.

Moore, E.S., Wilkie, W.L. and Desrochers, D. M. (2016), “All in the Family? Parental roles in the epidemic of childhood obesity”, Journal of Consumer Research, Vol. 43 No. 5, pp. 824-859.

Morgan, D.H.J. (1996), Family Connections, Polity Press, Cambridge.

Murphy, E. (1999), “'Breast is Best': infant-feeding decisions and maternal deviance”, Sociology of Health \& Illness, Vol. 21 No. 2, pp. 187-208. 
Murphy, E. (2000), “Risk, Responsibility, and Rhetoric in Infant Feeding”, Journal of

Contemporary Ethnography, Vol. 29 No. 3, pp. 291-325.

Murcott, A. (2012), "Lamenting the "decline of the family meal" as a moral panic?: methodological reflections", Recherches Sociologiques et Anthropologiques, Vol. 43 No. 1, pp. 97-118. Available at http://journals.openedition.org/rsa/845?lang=en\#toc (Accessed 19/05/18)

Nasser, M. (1997), Culture and Weight Consciousness. Routledge, London and New York

Nasser, M., Katzman, M. A. and Gordon, R. A. (2002), Eating Disorders and Cultures in

Transition. Brunner-Routledge, New York.

NHS Choices (2018), Pregnancy https://www.nhs.uk/conditions/pregnancy-and-baby/healthy-

pregnancy-diet/? (accessed Jan 30 2018)

NHS Choices (2018), Pregnancy, preconception and nutrition

https://www.nutrition.org.uk/nutritionscience/life/pregnancy-and-pre-

conception.html?limit=1\&start=1 (accessed Jan 30 2018).

Norman, H. Elliot, M., Fagan, C. (2014), "Which fathers are the most involved in taking care of their toddlers in the UK? An investigation of the predictors of paternal involvement", Community, Work \& Family, Vol. 17 No. 2, pp. 163-180.

Oláh, LS (2013), “Interview with Population Europe’s Insa Cassens on the launch of the Changing Families and Sustainable Societies: Policy contexts and diversity over the life course and across generations" Project in Sweden”, Accessed online@http://www.populationeurope.eu/statement/family-change-not-over. (accessed 23/05/18).

O’Malley, P. (2009), "Responsibilization” in Wakefield, A. and Flemming, J. (Eds.) The Sage Dictionary of Policing, Sage, London and Thousand Oaks CA.

ONS (2013), "Women in the Labour Market", available at https://www.ons.gov.uk/employmentandlabourmarket/peopleinwork/employmentandemployeetypes /articles/womeninthelabourmarket/2013-09-25 (accessed 19/05/18) 
Petersen, A. and Lupton, D. (1996), The New Public Health: Health and Self in the Age of Risk. Sage, London.

Petersen, A., Tanner, C. and Fraser, S. (2014), "Practicing food anxiety: making Australian mothers responsible for their families' dietary decisions", Food and Foodways, Vol. 22 pp. 175-197.

Pollan, M. (2013), Cooked: A Natural History of Transformation. Penguin Press, London.

Russell, G. (1986), “Primary Caring and Role Sharing Fathers”, in Lamb, M.E. (Ed.) The Father's Role: Applied Perspectives, John Wiley \& Sons, New York.

Schneider, T., Eli, K., Dolan, C. and Ulijaszek, S. (Eds.) (2018), Digital Food Activism. Routledge, London.

Schneider, T. and Davis, T. (2010), “Advertising food in Australia: Between antinomies and gastro - anomy", Consumption, Markets and Culture, Vol. 13 No. 1, pp. 31-41, DOI: $10.1080 / 10253860903346740$.

Scrinis, G. (2013), Nutritionism: The Science and Politics of Dietary Advice. Columbia University Press, Columbia.

Szabo, M. (2013), “Foodwork or foodplay? Men’s domestic cooking, privilege and leisure”, Sociology, Vol. 47 No. 4 pp. 623-638.

Szabo, M. (2014), "Men nurturing through food: challenging gender dichotomies around domestic cooking”, Journal of Gender Studies, Vol. 23 No. 1, pp. 18-31.

Thompson, C. J. (1996), “Caring consumers: Gendered consumption meanings and the juggling lifestyle”, Journal of Consumer Research, Vol. 22 pp. 388-407.

Triggle, N. (2018), “Soft drink sugar tax starts, but will it work?”, available at http://www.bbc.co.uk/news/health-43659124 (Accessed 23/05/18).

Ungerson, C. (1983), “Why do Women Care?”, in Finch, J. and Groves, D. (Eds.) A Labour of Love: Women, Work and Caring Routledge, Kegan and Paul, London.

U.S. Government advice on pregnancy and nutrition https://medlineplus.gov/pregnancyandnutrition.html (Accessed 30/01/18.). 
Waerness, K. (1984), “The Rationality of Caring”, Economic and Industrial Democracy, Vol. 5 No. 2, pp. $185-211$.

Wall, G. and Arnold, S. (2007), "How involved is involved fathering? An exploration of the contemporary culture of fatherhood", Gender and Society, Vol. 21 No. 4, pp. 508-26.

Warde A. (1997), Consumption, Food and Taste: Culinary Antinomies and Commodity Culture. Sage, London.

Warin M. (2011), “Foucault's progeny: Jamie Oliver and the art of governing obesity”, Social Theory and Health, Vol. 9 No. 1, pp. 24-40.

Worden, J. William (1991), Grief Counselling and Grief Therapy: a handbook for the mental health practitioner 2nd ed., London, Routledge.

Yates, L. and Warde, A. (2017), "Eating together and eating alone: Meal arrangements in British households", British Journal of Sociology, Vol. 68 No. 1, pp. 97-118.

Zelizer, V.A. (2005), The Purchase of Intimacy. Princeton University Press, Princeton, NJ.

\footnotetext{
ii Leverhulme International Network F/00 158/CS collaboration between University of Edinburgh, University of Sydney, Lancaster University, University of Oxford, Monash University.
} 